\title{
Detección citológica inusual de huevos de Enterobius vermicularis en orina y en frotis cervicouterino
}

\author{
Nery Romero, Marlene Vargas \\ Hospital Nacional Docente San Bartolomé, Lima, Perú
}

\begin{abstract}
Introducción: La parasitosis por Enterobius vermicularis es frecuente en el tracto intestinal en niños; en adultos es infrecuente, pero más infrecuente aún son las afecciones extraintestinales. Se ha comunicado infecciones raras formando nódulos granulomatosos en hígado, pulmón, ovario, vulva, epiplón, piel, periné, formando abscesos tuboováricos, pélvicos y subcutáneos; así mismo, produciendo lesiones en riñón, ojo, glándula submandibular, próstata y mucosa nasal. Algunos casos se presentaron semejando tumores. El diagnóstico se realizó por observación directa de parásitos adultos en endoscopias y cirugías, por estudio histopatológico de biopsias o por medio del estudio citológico de frotices o aspirados de las lesiones.

Objetivos: Comunicar el hallazgo inusual en dos casos de diagnóstico citológico de huevos de Enterobius vermiculares.
\end{abstract}

Diseño: Estudio de casos.

Institución: Hospital Nacional Docente San Bartolomé, Lima, Perú.

Intervenciones: Estudio citológico de orina y de frotis cérvico uterino mediante la técnica de Papanicolaou.

Participantes: Dos pacientes.

Principales medidas de resultados: Hallazgo de huevos de Enterobius vermicularis.

Resultados: Se presenta dos casos de diagnóstico citológico de huevos de Enterobius vermicularis, el primero en un examen citológico de Papanicolaou en frotis cérvico uterino de una mujer de 35 años, multípara, no gestante y sin datos clínicos de importancia, y el segundo en un examen de urocitograma de una niña de 9 años, quien tenía un cuadro de pubertad precoz.

Conclusiones: El hallazgo extraintestinal o ectópico del Enterobius vermiculares es infrecuente y la citología es uno de los mejores instrumentos para la identificación de estos parásitos.

Palabras clave: Huevos de Enterobius vermicularis, frotis cérvico uterino, orina.

\section{Incidencia del cáncer de vesícula biliar en pacientes colecistectomizados por litiasis: $\mathbf{5}$ años de experiencia en el HNERM}

José M. Ortiz, Elydia Mujica, Duber Gallardo

Instituto Nacional de Biologia Andina, Facultad de Medicina, UNMSM, y Hospital Nacional Edgardo Rebagliati Martins, EsSalud

Objetivos: Determinar la incidencia de cáncer de vesícula biliar en pacientes colecistectomizados por litiasis vesicular. Diseño: Descriptivo, observacional.

Institución: Instituto Nacional de Biología Andina, Facultad de Medicina, UNMSM, y Hospital Nacional Edgardo Rebagliati Martins, EsSalud.

Material anatomopatológico: Informes de diagnóstico anatomopatológico de colecistectomías recibidas.

Intervenciones: Revisión de 12966 informes de diagnóstico anatomopatológico de colecistectomías recibidas en el Servicio de Patología Quirúrgica, desde el año 2003 hasta el 2007.

Principales medidas de resultados: Incidencia de cáncer de vesícula biliar y su estratificación por edad y género.

Resultados: Se registró 92 casos de cáncer, con lo cual se obtuvo una incidencia promedio de $0,71 \%$. Dado el volumen de colecistectomías, en el HNERM se observó la presentación de cáncer en uno a dos casos por mes. El 100\% de estos casos correspondía a adenocarcinoma, 93,7\% a personas mayores de 50 años y $69,7 \%$ a mujeres.

Conclusiones: El carcinoma de vesícula biliar es una neoplasia maligna relativamente rara. Sin embargo, el porcentaje de pacientes con diagnóstico de cáncer de vesícula biliar luego de colecistectomía simple debida a cálculos biliares fue $0,71 \%$. Si bien es cierto la incidencia fue relativamente baja, se recomienda el estudio histopatológico de las piezas de colecistectomía, debido a su baja sospecha diagnóstica clínica, imagenológica y quirúrgica.

Palabras clave: Cáncer de vesícula biliar. 